\title{
Blindness in Africa: Zimbabwe schools for the blind
}

\section{survey}

Larry Schwab, Kenneth Kagame

\begin{abstract}
An ophthalmic assessment survey of 430 students in Zimbabwe's two schools for the blind was conducted in 1988. Bilateral corneal opacity was found to be responsible for $75 \%$ of all blindness among institutionalised blind students. Thirteen per cent of the study patients could gain improved vision through either ocular surgical intervention or spectacle correction. Findings in this survey are similar to those from other schools for the blind elsewhere in Africa.
\end{abstract}

(Brf Ophthalmol 1993; 77: 410-412)

Blindness in children and young adults is a major public health problem in Africa. Blindness which occurs in childhood is the precursor of a lifetime of economic and social deprivation for hundreds of thousands of African children. Each blind child represents a social and economic burden for the family which is exacerbated as the person develops into adulthood. Collectively, the total blind community in every developing country where preventable blindness is a public health problem represents a sizeable economic and social burden for the government and society.

There are approximately 270000 blind African children less than 15 years of age. ${ }^{1}$ Taking into account the African life expectancy of 51 years, ${ }^{2}$ these statistics may be further

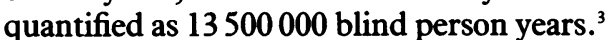

Surveys of institutionalised blind students have been conducted in several African nations. ${ }^{45}$ A survey of all students living and studying at schools for the blind in Zimbabwe was undertaken in 1988 (1) to determine causes of blindness and reasons for admission to a school for the blind, and (2) to obtain baseline data for organisations, both governmental and nongovernmental, which work towards the prevention of blindness and the rehabilitation of blind children and adults in Zimbabwe.

West Virginia School of Medicine, Morgantown, West Virginia, USA L Schwab

Jinja Hospital, Uganda K Kagame

Correspondence to:
Larry Schwab, MD, Larry Schwab, MD, Bethesa, MD 20814, USA Bethesa, MD 20814, USA. Accepted for publication 27 November 1992 ject included visual acuity measurement (with Snellen optotypes when indicated) and examination of the anterior segment with a handlight and a $2 \cdot 5 \times$ magnifying loupe by both examiners. Neither a static nor a portable slit-lamp were

\section{Methods}

A total of 430 students living and studying at the examined. Medical history included ques designed to determine cause and age of onset of blindness. Parental histories were not available health records very often were incomplete.

. available for use in the survey. This methodology parallels that of other surveys of schools for the blind in Africa. ${ }^{146}$ Direct ophthalmoscopy was performed whenever possible in eyes with media sufficiently clear to allow access to the ocular fundus. Students requiring surgery were referred to the Sekuru Kaguvi Eye Hospital of Parirenyatwa Hospital in Harare, one of two referral tertiary hospitals in Zimbabwe.

\section{Results}

At the time the survey was conducted, there were 430 students (253 male; 177 female) in Zimbabwe's two blind schools. The male:female ratio was 1:1 for all students less than 10 years of age. The male:female ratio was $1 \cdot 5: 1$ for all students older than 10 years of age. Age and sex distribution data are displayed in Figure 1.

Classification of visual disability and blindness followed the World Health Organisation grading system. By these criteria, all students with visual acuity in the better eye of less than $3 / 60$ (WHO category III) were classified as blind. According to this classification, $362(84 \cdot 2 \%)$ of the students were blind, $37(8.6 \%)$ had severe visual impairment (WHO category II, visual acuity less than $6 / 60$ and equal to or better than $3 / 60), 26(6 \%)$ had moderate visual impairment, and five $(1 \cdot 2 \%)$ were normally sighted.

Two hundred and forty eight (58\%) of all students had a visual acuity of NLP (no light perception - WHO blindness category V). According to medical histories from the students, measles was responsible for $72 \cdot 5 \%$ ( 180 students) of all students with no light perception. Visual acuity results are given in Table 1 .

Causes of blindness, in descending order of frequency, were corneal opacity $(75 \%)$, posterior segment and central nervous system pathology (9\%), cataract $(7 \%)$, and miscellaneous $(9 \%)$. Eighty one per cent of all corneal blindness was attributable to measles.

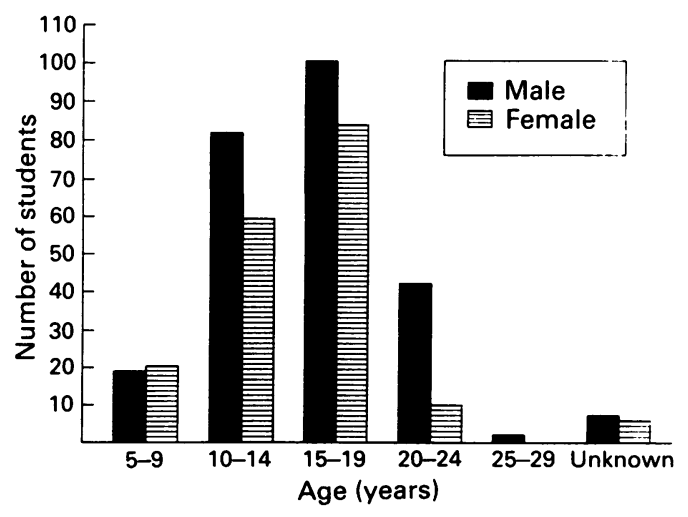

Figure 1 Survey of blind students in Zimbabwe in 1988. 
Congenital cataract was the most frequently diagnosed congenital anomaly (27) followed by congenital glaucoma (eight). Eighteen students were institutionalised because of optic atrophy. Bilateral pigmented tapetoretinal degenerations were diagnosed in 13 students. Causes of blindness are shown in Table 2.

Students who were considered to have salvageable vision and whose eyesight could possibly be improved by surgical intervention were referred to the tertiary ocular unit at Sekuru Kaguvi Eye Hospital in Harare. Because corneal donor material was not available in Zimbabwe, optical iridectomy was the most frequently recommended surgical operation for corneal opacity. Cataract surgery was the second most frequently recommended operation. Data regarding sightrestoring intervention are given in Table 3.

\section{Discussion}

Available data suggest that there are approximately 1.5 million blind children in the world, of which $90 \%$ live in developing nations.' Our study included children less than 15 years of age, together with young adults living and learning at the schools for the blind.

Corneal opacity was the most frequent clinical finding responsible for blindness and visual impairment among students in Zimbabwe's blind schools. Corneal opacity accounted for $75.3 \%$ of blindness among these institutionalised individuals, a statistic which is similar to data from similar studies in Africa ${ }^{4689}$ (Table 4).

Endstage corneal disease and morphology of corneal opacity is neither a sensitive nor a specific indicator of its aetiology. Although individual histories are not considered entirely reliable, they do provide information regarding previous infectious and traumatic events which can contribute to corneal opacity.

In order to determine the aetiology of a corneal opacity, the lesion must be studied longitudinally during its evolution. Although it is not always possible in outpatient clinics in Africa, the bacterial, fungal, and viral corneal pathogens should be investigated during the evolution of corneal ulcer to opacity. In this regard, laboratory investigation studies by Foster and Sommer ${ }^{10}$ and Sanford-Smith ${ }^{8}$ into the infective and inflammatory aetiologies of corneal opacity are relevant. Foster, in his study of Tanzanian children presenting with corneal ulcers, found that $26 \cdot 2 \%$ were related to vitamin A deficiency. Thirty seven per cent of all ulcers in Foster's study were precipitated by acute measles.

Bacterial keratoconjunctivitis, herpes simplex keratitis, and trauma were the major causes of monocular corneal ulceration in Foster's study whereas vitamin A deficiency, traditional eye medications, and measles were the major causes of bilaterial corneal ulceration in the same study. In Sanford-Smith's study in Nigeria, $\mathbf{9 0 \%}$ of active corneal ulcers were precipitated by measles associated with protein-energy malnutrition and not strictly isolated vitamin A deficiency. It should be pointed out that, in the latter study, punctate keratitis in acute measles infection was classified as corneal ulcer.

These two studies are in agreement concern- ing the significance of measles as an earlier and precipitating factor to childhood inflammatory corneal disease but they are not in agreement on the issue of a micronutrient (vitamin A) deficiency or macronutrient (protein-energy) deficiency as the underlying nutritional cause. The major risk factor for childhood inflammatory corneal disease in Africa (and subsequent corneal opacity and bilateral blindness) could be appropriately described as 'measles-malnutrition' complex. It appears that this risk factor accounts for $50-70 \%$ of bilateral blinding corneal opacity in Africa.

Congenital aetiologies account for approximately $50 \%$ of all childhood blindness in industrialised nations. " This is in contrast to the situation in Africa, where corneal opacity is

Table 1 Visual acuities of 430 students surveyed in Zimbabwe schools for the blind according to the WHO classification

\begin{tabular}{lcc}
\hline WHO category & $\begin{array}{c}\text { Number } \\
\text { of children }\end{array}$ & $\begin{array}{c}\text { Percentage } \\
\text { of total }\end{array}$ \\
\hline $\begin{array}{l}\text { Category 0 } \\
\text { VA better than 6/18 }\end{array}$ & 5 & $1 \cdot 2$ \\
$\begin{array}{l}\text { Category 1 } \\
\text { VA less than 6/18 and better or equal to 6/60 }\end{array}$ & $6 \cdot 0$ \\
$\begin{array}{l}\text { Category 2 } \\
\text { VA less than } 6 / 60 \text { and better or equal to 3/60 }\end{array}$ & $8 \cdot 6$ \\
$\begin{array}{l}\text { Category 3 } \\
\text { VA less than } 3 / 60 \text { and better or equal to } 1 / 60\end{array}$ & $8 \cdot 8$ \\
$\begin{array}{l}\text { Category 4 } \\
\text { VA less than } 1 / 60 \text { and better or equal to light perception } \\
\text { Category 5 } \\
\text { VA no light perception }\end{array}$ & 248 & $57 \cdot 7$ \\
$\begin{array}{l}\text { Not recorded } \\
\text { Total }\end{array}$ & 5 & $1 \cdot 2$ \\
\hline
\end{tabular}

Table 2 Causes of blindness

\begin{tabular}{lrr}
\hline Causes & Number & Percentage \\
\hline Corneal opacity & & \\
$\quad$ Measles & 288 & $67 \cdot 0$ \\
$\quad$ Non-measles & 35 & $8 \cdot 2$ \\
Posterior segment & 39 & $9 \cdot 1$ \\
$\quad$ (retina, vitreous, optic nerve, CNS, & & \\
$\quad$ congenital, and developmental) & & \\
Cataract & & \\
$\quad$ Congenital & 27 & $6 \cdot 2$ \\
$\quad$ Complicated & 3 & $0 \cdot 7$ \\
Uveitis & 8 & $1 \cdot 9$ \\
Glaucoma, congenital & 8 & $1 \cdot 9$ \\
High myopia & 5 & $1 \cdot 1$ \\
Others & 17 & $3 \cdot 9$ \\
Total & 430 & $100 \cdot 0$ \\
\hline
\end{tabular}

Table 3 Diagnosis and planned intervention for $55(12 \cdot 8 \%)$

\begin{tabular}{lll}
\hline Diagnosis & Intervention & Number \\
\hline Corneal opacity & Optical iridectomy & 32 \\
Cataract & Cataract surgery & 8 \\
Aphakia & Refraction & 8 \\
Myopia & Refraction & 5 \\
Staphyloma & Enucleation & 1 \\
Glaucoma & Filtering surgery & 1 \\
Total & & $55(12 \cdot 8 \%)$ \\
\hline
\end{tabular}

Table 4 Comparative data of corneal opacity and measles as a cause of blindness in children

\begin{tabular}{llll}
\hline Country & Year (ref) & $\begin{array}{l}\text { Comeal opacin } \\
\text { as\% causing } \\
\text { blindness }\end{array}$ & $\begin{array}{l}\text { Measles } \\
\text { histony } \\
(\%)\end{array}$ \\
\hline Zambia & $1967(6)$ & 80 & 50 \\
Malawi & $1976(4)$ & 75 & +4 \\
Zimbabwe & $1988(3)$ & 75 & 67 \\
Saudi Arabia & $1988(13)$ & 75 & Unknown \\
Tanzania & $1978(5)$ & 70 & 50 \\
Nigeria & $1977(8)$ & 69 & +2 \\
Jamaica & $1988(12)$ & 5 & 0 \\
Lebanon & $1975(14)$ & 4 & Unknown \\
Australia & $1969(11)$ & 0.5 & 0.5 \\
\hline
\end{tabular}


responsible for most blindness among children and young adults. African data also differ significantly from data from Jamaica, ${ }^{12}$ Saudi Arabia, ${ }^{13}$ and Lebanon, ${ }^{14}$ although the latter three are not so-called 'developing' countries. Jamaica, Saudi Arabia, and Lebanon each have in place an effective national measles control programme. That may be a major factor reducing bilateral corneal opacity as significant aetiology of bilateral blindness in those countries.

\section{Conclusions}

Corneal opacity is responsible for $75 \%$ of blindness among all students in schools for the blind in Zimbabwe. This figure is similar to data from similar studies in Africa.

Nearly $13 \%$ of institutionalised blind students in Zimbabwe in 1988 required surgery or refraction to correct significant visual loss. Fully $10 \%$ required sight-restoring or sight-preserving surgery, including those who were bilaterally blind from corneal opacity, congenital cataract, and congenital glaucoma.

An expanded programme of immunisation including measles and programmes to elevate the standard of living and nutritional status of those children born into deprived communities can lower both the incidence and prevalence rates of bilateral corneal blindness in Zimbabwe.

Regular surveillance of institutionalised blind students in Africa performed by ophthalmic teams can identify those individuals who will benefit from surgery.
The officers and faculty of Zimbabwe's schools for the blind in Kadoma and Masvingo and the Jairos Jiri Foundation, who provided assistance, and Dr Allen Foster of the International Centre for Eye Health, London, who reviewed the manuscript, are gratefully acknowledged.

Dr Larry Schwab, adviser to the International Eye Foundation, formerly was an honorary lecturer, University of Zimbabwe School of Medicine and currently is adjunct associate professor of phthalmology and community medicine, West Virginia School of Medicine, Morgantown, West Virginia, USA, and adjunct associate professor of tropical

Orleans, Louisiana, USA. Dr Kenneth Kagame, an ophthalmic consultant with Sight
Savers of England serving at Jinja Hospital, Uganda, formerly was a lecturer at the University of Zimbabwe.

1 Chirambo MC, Tielsch JM, West KP, Katz J, Tizazu T, Schwab $L$, et al. Blindness and visual impairment in southern Malawi. Bull WHO 1986; 64: 567-72.

2 Population Reference Bureau, Inc. World Population Data Sheet, Washington, DC, 1987.

3 Kagame K, Schwab L. Childhood blindness: dateline Africa. Ophthalmic Surg 1989; 20: 128-31.

4 Chirambo MC, Ben-Ezra D. Causes of blindness among students in a blind school institution in a developing students in a blind school institution

5 Sauter JJ. Causes of blindness detected in nineteen schools for the blind in Tanzania. A final report for the Ministry of Health, Dar es Salaam, 1979.

6 Audry PN, Adams PCG. Blindness in Luapula Valley. Centra Afr f Med 1967; 13: 197-201.

7 Foster A. Childhood blindness. Eye 1988; 2 (suppl): s27-36.

8 Sandford-Smith JH, Whittle HC. Corneal ulceration following measles in Nigerian children. Br 7 Ophthalmol 1979; 63: $720-4$.

9 Faal H, Minassian D. National survey of blindness and eye disease in Gambia: results. Br $\mathcal{F}$ Ophthalmol 1989; 73: 82-7.

10 Foster A, Sommer A. Corneal ulceration, measles, and childhood blindness in Tanzania. Br f Ophthalmol 1987; 71: 331-43.

1 Fraser GR. Causes of severe visual handicap among schoo children in Southern Australia. Med $\mathcal{F}$ Aust 1968; 1: 615-20. 12 Moriarty BJ. Childhood blindness in Jamaica. Brf Ophthalmo 1988; 72: 65-7.

13 Tabbara KF, Badr IA. Changing pattern of childhood blindness in Saudi Arabia. Br7 Ophthalmol 1985; 69: 312-5.

14 Baghdassarian SA, Tabbara KF. Childhood blindness in Lebanon. Am $\mathcal{F}$ Ophthalmol 1975; 79: 827-30. 